\title{
Correlation analysis of the vertebral compression degree and CT Hounsfield units in elderly patients with osteoporotic thoracolumbar fractures
}

Cheng Li

Fifth Clinical Medical College, Guilin Medical University

Wei Hu ( $\square$ howie189@126.com)

Fifth Clinical Medical College, Guilin Medical University

Yang Lin

Fifth Clinical Medical College, Guilin Medical University

Xingming Lai

Fifth Clinical Medical College, Guilin Medical University

Xinyu Huang

Fifth Clinical Medical College, Guilin Medical University

\section{Research Article}

Keywords: CT Hounsfield units, osteoporotic thoracolumbar fractures, BMD, cancellous bone

Posted Date: January 12th, 2022

DOI: https://doi.org/10.21203/rs.3.rs-1042970/v1

License: (9) This work is licensed under a Creative Commons Attribution 4.0 International License. Read Full License 


\section{Abstract \\ Background}

To explore the correlation analysis of the vertebral compression degree and cancellous bone CT Hounsfield units (HUs) in elderly patients with osteoporotic thoracolumbar fractures.

\section{Methods}

Forty-five elderly patients (32 females and 13 males) with single acute vertebral fragility fractures were retrospectively reviewed, and thoracolumbar MRI was used to assess whether each patient's vertebral compression fracture was fresh and whether the fractured vertebral body was single.All patients were diagnosed with osteoporosis or osteopenia by DXA.The consistency of measurement between two spine surgeons were evaluated. If the cancellous bone CT HU values of the vertebral bodies could not be measured due to moderate or severe compression, the average cancellous bone CT HU values of the upper and lower vertebral bodies were used instead.

\section{Results}

There were $18 \mathrm{~L} 1$ vertebral fractures, $16 \mathrm{~T} 12,6 \mathrm{~L} 2,3 \mathrm{~T} 11$, and $2 \mathrm{~T} 10$ fractures. The patients' average age was $70.89 \pm 9.59$ years (53 to 94 years), and the average CT HU value was $92.01 \pm 34.11 \mathrm{HU}$ (36 to $167 \mathrm{HU}$ ). The average vertebral compression ratio was $0.54 \pm 0.16$ (0.26 to 0.83).Measurements showed both good intrarater repeatability and good interrater reproducibility of the vertebral compression ratio (the intraclass correlation coefficient (ICC) was 0.982). The degree of vertebral compression in thoracolumbar osteoporotic fractures was highly positively correlated with the CT HU values of cancellous bone $(\mathrm{P} \bowtie 0.01)$.

\section{Conclusions}

This study provides the quantitative evidence that the degree of thoracolumbar osteoporotic compression fracture is associated with the CT HU units of cancellous bone in elderly patients. Further longitudinal studies with larger cohorts are needed to verify this relationship.

\section{Background}

With an aging population, osteoporosis is becoming a global problem and affects 200 million people worldwide [1]. Spinal vertebral fractures are the most common form of osteoporotic fracture, followed by fractures of the femoral proximal and distal radius.Due to specific spine biomechanical conduction [2], the thoracolumbar vertebral body (T10-L2) is the easiest vertebral body to fracture in spine trauma. 
Dual-energy X-ray absorptiometry (DXA) is currently considered to be the gold standard for bone mineral density (BMD) quantification and has been shown to correlate with fracture risk and the efficacy of treatment [3].However,BMD is one of the risk factors for fracture, some fragility fractures occur in individuals with BMD T values above the -2.5 threshold, which suggests that BMD has limited value for the prediction of osteoporosis in the clinic [4,5]. BMD is also the most commonly used method for evaluating bone density in spine surgery. Elderly patients with osteoporotic fractures tend to merge degenerative diseases, however, lumbar degenerative diseases easily leads to increased pseudo DXA measurement values, cause osteoporosis diagnosis.It has been proven [6] that the prevalence of osteoporosis in patients with lumbar degenerative disease is high, and the rate of missed diagnosis by DXA is also high.It is insufficient to use DXA alone to assess BMD in patients with lumbar degenerative disease.

Studies $[7,8]$ have found that the CT HU value of the vertebral trabecular (noncortical) region can reflect the $\mathrm{BMD}$, and routine $\mathrm{CT}$ examination can be used to identify patients with osteoporosis. It is recommended that the CT HU value of the vertebral body be combined to improve the accuracy of BMD assessment.CT HU values can also be used to assess the risk of thoracolumbar vertebral fragility fractures. The lower the CT HU values of the vertebral body, the higher is the risk of frangible fracture of the vertebral body, and the greater is the number of vertebral fractures that may exist [9].In addition, there is no research using vertebral CT HU values to qualitatively analyze the severity of vertebral body osteoporotic fractures. For this reason, this study aimed to further explore the relationship between osteoporotic vertebral cancellous bone fracture CT HU values and the severity of vertebral compression fractures.

\section{Methods}

\section{Patient cohort}

This study was reviewed and approved by the Fifth Clinical Medical College of Guilin Medical University. The informed consent requirement was waived because this study was retrospective. All methods were performed following relevant guidelines and regulations.

All patient data were retrieved retrospectively from our institute's radiology information system. We reviewed elderly patients undergoing surgery for acute vertebral fragility fractures in our department from January 2019 to December 2020. Inclusion criteria were (1) a single segment of the acute vertebral compression fractures (positioned in T10 - L2); (2) no obvious history of high-energy trauma; (3) clear magnetic resonance imaging (MRI) and CT scan images for DXA diagnosis of osteoporosis or osteopenia; and (4) no history of spinal surgery associated with disease. Exclusion criteria were (1) a single segment of acute vertebral compression fractures outside the thoracolumbar location and more segmental frangible compression fractures; (2) a clear history of high-energy injury; (3) no concurrence with MRI, CT, or DXA imaging scans; (4) old vertebral compression fractures; (5) a secondary osteoporosis fracture (oral hormone usage, etc.), pathological (metastases) and ankylosing spondylitis 
fractures; (6) postoperative status, or known history of disability; and (7) history of spinal surgery associated with disease.

All patients underwent a routine MRI study of the thoracolumbar spine in the supine position.Sagittal or coronal T2-weighted fat-saturated MRI images were used to assess acute vertebral compression fractures. The degree of vertebral compression and the CT HU values of cancellous bone were measured by three-dimensional CT scans.

\section{CT and measurements}

All MRI scans were performed using either of two 1.5-T scanners (Signa, GE Healthcare). The thoracolumbar vertebral body was chosen as the site for CT HU value measurements with preoperative three-dimensional reconstructive spinal CT scans (American GE Company, Light Speed VCT, scanning conditions: tube voltage: $120 \mathrm{kV}$, tube current: $355 \mathrm{~mA}$, slice thickness: $5 \mathrm{~mm}$, slice spacing: $5 \mathrm{~mm}$, bone window width: $2000 \mathrm{HU}$, window level: $350 \mathrm{HU}$ ). The picture archiving and communication system (PACS) was used to measure the vertebral compression degree and cancellous bone CT HU values. The oval region of interest (ROI) was placed on the middle-axial image within the trabecular bone of the thoracolumbar vertebral body; however, the vertebral venous plexus, cortical bone, hyperosteogeny and artifacts should be avoided [10-12]. Through the analysis of two spine surgeons independently assessing the axial CT measurement of vertebral cancellous bone fracture CT HU values on a single axial CT image at the appropriate level by manually placing, it was proven that CT HU measurements have excellent interobserver and intraobserver reliability $[13,14]$. If the compressed vertebral body had moderate to severe fractures, the average CT HU values of the superior and inferior vertebral bodies of the compressed vertebral body were used instead (Fig. 1).Commonly, osteoporotic vertebral compression fractures compression ratio is the low of sagittal scan compressed vertebral bodies and the same height of vertebral rear on the three-dimensional CT. And if whole-body compression occurred, the degree of compression was calculated as the ratio of the height of the lowest compressed vertebral body to that of the posterior edge of the superior vertebral body (Fig. 2) [9, 15].

\section{Statistical analyses}

The statistical analysis in this study was conducted using SPSS version 26 (SPSS, USA). Input and analysis of measured data and measurement data were recorded as means \pm standard deviations. Two spinal surgeons measured the data consistency inspection. Intrarater repeatability was assessed using the intraclass correlation coefficient (ICC) to determine the reliability. Using the Spearman correlation test to correlation analysis both vertebral compression degree and cancellous bone CT HU values in thoracolumbar osteoporotic fracture. $\mathrm{P}<0.01$ was considered to indicate a statistically significant difference.

\section{Results}


A total of 45 elderly patients with 32 females and 13 males were included in the final analysis. These included $18 \mathrm{~L} 1$ osteoporotic vertebral fractures, 16 T12 fractures, 6 L2 fractures, 3 T11 fractures, and 2 T10 fractures. The patients' average age was $70.89 \pm 9.59$ years (53 to 94 years), and the average CT HU value was $92.01 \pm 34.11 \mathrm{HU}$ ( 36 to $167 \mathrm{HU})$. The average vertebral compression ratio was $0.54 \pm 0.16(0.26$ to 0.83$)$..

\section{Consistency test}

The consistency of the measurement results of the two spine surgeons was tested, and the consistency of the compression ratio data of thoracolumbar fractures was evaluated $(I C C=0.982>0.75)$. The consistency of the data measured by the two spine surgeons was high (Table 1).

Table1 Consistency test of fracture vertebral compression ratio measured by two spinal surgeons

\begin{tabular}{|llllllll|}
\hline & $\begin{array}{l}\text { Intra-class } \\
\text { correlation }\end{array}$ & \multicolumn{3}{l}{$\begin{array}{l}\text { 95\% confidence } \\
\text { interval }\end{array}$} & & \multicolumn{4}{ll}{ F-test with Ture value 0 } \\
\cline { 3 - 7 } & & $\begin{array}{l}\text { Lower } \\
\text { Limit }\end{array}$ & $\begin{array}{l}\text { Upper } \\
\text { limit }\end{array}$ & Value & df1 & df2 & Significance \\
\hline $\begin{array}{l}\text { Single } \\
\text { Measurement }\end{array}$ & .964 & .935 & .980 & 56.298 & 44 & 44 & .000 \\
\hline $\begin{array}{l}\text { Average } \\
\text { measurement }\end{array}$ & .982 & .966 & .990 & 56.298 & 44 & 44 & .000 \\
\hline
\end{tabular}

\section{Correlation between vertebral compression degree and cancellous bone CT HU values in thoracolumbar osteoporotic fracture}

The degree of vertebral compression in thoracolumbar osteoporotic fracture was correlated with the CT $\mathrm{HU}$ value of cancellous bone (P囚0.01), and the correlation coefficient was $r=0.645$ (Table 2). The degree of vertebral compression in thoracolumbar osteoporotic fracture was highly positively correlated with the CT value of cancellous bone (Fig. 3).

Table2: Spearman correlation test of vertebral compression ratio and CT HU value 


\begin{tabular}{|c|c|c|c|}
\hline & & Vertebral compression ratio & CT HU value \\
\hline & Spearman correlation & 1.000 & $.645^{\star \star}$ \\
\hline \multirow[t]{2}{*}{ Vertebral compression ratio } & $P$ & & 0.000 \\
\hline & $\mathrm{N}$ & 45 & 45 \\
\hline \multirow[t]{3}{*}{ CT HU value } & Spearman correlation & $.645^{\star \star}$ & 1.000 \\
\hline & $P$ & 0.000 & \\
\hline & $\mathrm{N}$ & 45 & 45 \\
\hline
\end{tabular}

Figure 3 The degree of vertebral compression in thoracolumbar osteoporotic fracture was highly positively correlated with the $C T$ value of cancellous bone $\left(R^{2}\right.$ liner $\left.=0.448\right)$

\section{Discussion}

Our study initially demonstrated that for osteoporotic vertebral fractures, with the decrease in cancellous bone CT HU values in the thoracolumbar segment (T10-L2), the degree of compression became increasingly obvious for low-energy vertebral bodies. There was a typical linear relationship between the degree of vertebral compression and the CT HU values of cancellous bone.In our study, patients had experienced a low-energy injury, and all patients were diagnosed with osteoporosis or osteopenia based on DXA bone mineral density after admission. MRI is currently the preferred imaging method for the diagnosis and treatment of fragile vertebral fractures [16], we used thoracolumbar MRI to assess that the patient's vertebral compression fracture was fresh and the fractured vertebral body was single.

The commonly used classification method for osteoporotic vertebral compression fractures was proposed by Genant et al[15],which is named the semipolicy (SQ) criteria,this approach involves the use of thoracolumbar lateral X-ray to determine the degree of vertebral compression, However, the angle of the subject to exposure, the patient position, the operation of the vertebral body levels morphology, and Xray technician experience, which in some cases may cause small errors in judgment of the degree of vertebral body compression. While computed tomography(CT) scans can make use of sagittal alignment evaluation, they are good enough to determine the degree of compression.Because of the limitations of the SQ criteria in assessing vertebral compression, we chose three-dimensional CT scans to assess vertebral compression in the sagittal plane of a frangible fracture.

The CT value represents the attenuation value of X-rays after they pass through the tissue and are absorbed. It is a unit for measuring the density of a local tissue or organ in the human body and is usually called the Hounsfield unit (HU). The CT HU value is based on water and is equal to the difference between the attenuation coefficient of the substance and the absorption coefficient of water multiplied by 
1000 after determining the ratio to the attenuation coefficient of water [12]. The CT HU value reflects the density of the material; the higher the density of the material is, the higher the CT HU value, so the human skeleton is no exception. The $\mathrm{HU}$ value for bone typically ranges from 300 to 3000[17]. Compared with DXA examination, CT HU value measurement in evaluating BMD confers an obvious advantage:(1) DXA measurement of BMD cannot distinguish between cortical bone or cancellous bone [8]. Moreover, a study [18] has suggested that cancellous bone in the spine plays a more important role in the process of loadbearing and compression fractures than does the bone cortex. (2) Conventional DXA can only detect the lumbar spine and hip BMD values of these easy-to-fracture positions. However, CT examination is not limited by the examination site, and a large number of high-risk groups of vertebral fragility fractures have not received standardized bone mineral density assessment. On the other hand, many elderly people have received clinical CT examinations for various diseases (chest CT, abdominal and pelvic CT, spinal $\mathrm{CT}$, urinary $\mathrm{CT}$, etc.). We can use these existing $\mathrm{CT}$ images to measure the $\mathrm{CT}$ HU value of the vertebral body to assess the BMD to easily and quickly identify patients at high risk of osteoporosis and brittle vertebral fracture. (3) The prevalence of row helical CT machines in medical institutions is significantly higher than that of DXA; at the same time, the measurement of $\mathrm{HU}$ is convenient and has good to excellent interactive tests between observers for reliability, which makes this method simple and easy to popularize [13].

At present, many conventional CT studies of osteoporosis fractures at the L1 vertebral level have been performed. Studies [19] have proven that conventional CT-measured CT HU values can be used to identify normal vertebral bone mass and osteoporosis. Emohare et al.[20] reported thoracolumbar compression fractures in elderly patients to have a value of approximately $110 \mathrm{HU}$, but approximately a quarter of the fractures in the elderly patients in the study were not caused by low-energy trauma. Lee et al.[10] reported the average L1-HU value of vertebral fractures in elderly patients to be approximately $85 \mathrm{HU}$, which was lower than the average L1-HU value of normal people (approximately $125 \mathrm{HU}$ ). However, the use of an enhanced CT contrast agent can increase the L1-HU value by an average of $11 \mathrm{HU}$ compared with that of plain CT [21]. Zou et al.[9] reported that the average L1-HU value of acute vertebral fragility fractures was 66.0 HU by age and sex matching, and the AUC value for predicting vertebral fragility fractures by the vertebral CT value was $0.77(95 \% \mathrm{Cl}, 0.70-0.85 ; \mathrm{P}<0.001)$. The cutoff values of vertebral CT values corresponding to $90 \%$ specificity and $90 \%$ sensitivity were $60 \mathrm{HU}$ and $100 \mathrm{HU}$, respectively, in the elderly population; conventional CT measured the CT value of L1 vertebral body trabecular bone, which is closely related to the occurrence of vertebral fracture, and L1 attenuation $\leq 90 \mathrm{HU}$ may represent the best threshold for determining the risk of osteoporotic vertebral fracture [10, 22].Schreiber et al.[12], using the polyurethane module through mechanical dynamics experiments, proved that the CT HU value has a significant correlation with the compressive strength of bone. At the same time, our study preliminarily demonstrated that for low-energy frangible fractures in elderly individuals, the lower the CT HU value of cancellous bone, the more serious was the loss of vertebral height; conversely, the higher the CT HU value of cancellous bone, the less obvious was the loss of vertebral height.

This study has two limitations.First, the sample size of patients was small because we used strict inclusion criteria for this retrospective investigation. Further longitudinal studies with larger cohorts are 
needed to verify this relationship. Second, we only studied the effect of the cancellous bone CT HU value on the vertebral body of frangible fractures; However, other studies [23] have shown that compression fractures are associated with paraspinal fractures. Muscles such as the psoas are related to volume reduction. Therefore, the factors related to the height loss of vertebral compression fractures are worthy of further study.

\section{Conclusions}

In conclusion, the CT HU values are one of the important factors affecting the compression degree in osteoporotic vertebral fracture. This study provides the first quantitative evidence that the degree of thoracolumbar osteoporotic compression fracture is associated with the CT HU value of cancellous bone in elderly patients. Further longitudinal studies with larger cohorts are needed to verify this relationship.

\section{Abbreviations}

DXA:Dual-energy X-ray absorptiometry;BMD:bone mineral density;ICC:intraclass correlation coefficient;HU:Hounsfield unit

\section{Declarations}

\section{Acknowledgments}

The authors would like to thank AJE (www.aje.com) for the manuscript review and editing support.

\section{Authors' contributions}

Cheng Li: Drafting the article or revising it critically for important intellectual content.

Wei Hu: Drafting the article or revising it critically for important intellectual content.

Yang Lin: Substantial contributions to conception and design, or acquisition of data, or analysis and interpretation of data.

Xinyu Huang: Substantial contributions to conception and design, or acquisition of data, or analysis and interpretation of data.

Xingming Lai: Substantial contributions to conception and design, or acquisition of data, or analysis and interpretation of data.

\section{Funding}

This research received no specific grant from any funding agency in the public, commercial, or not-forprofit sectors. 
Availability of data and materials

The datasets generated during and/or analysed during the current study are available in the Guilin Medical University Library's repository, [https://mgmt.glmc.edu.cn/tsg/dzzy/zjsjk.htm].

\section{Ethics approval and consent to participate}

The study was approved by the licensing ethical committee of Fifth Clinical Medical College,Guilin Medical University, and the informed consent requirement was waived because this study was retrospective.All procedures performed in studies involving human participants were in accordance with the ethical standards of the institutional and/or national research committee and with the $1964 \mathrm{Helsinki}$ declaration and its later amendments or comparable ethical standards.

\section{Consent for publication}

Not applicable

\section{Conflicts of interest/Competing interests}

Cheng Li,Wei Hu,Yang Lin,Xinyu Huang and Xingming Lai declare that they have no conflict of interest.

\section{Author details}

${ }^{102}$ Department of Orthopaedics,Fifth Clinical Medical College,Guilin Medical University,7 Wenming Road,541002 Guilin,Guangxi Province, China

\section{References}

1. Cotts KG, Cifu AS (2018) Treatment of osteoporosis. JAMA 319:1040-1041. https://doi.org/10.1001/jama.2017.21995

2. Wood KB, Li W, Lebl DR, Ploumis A (2014) Management of thoracolumbar spine fractures. Spine J 14:145-164. https://doi.org/10.1016/j.spinee.2012.10.041

3. Marshall D, Johnell O, Wedel H (1996) Meta-analysis of how well measures of bone mineral density predict occurrence of osteoporotic fractures. BMJ 312:1254-1259. https://doi.org/10.1136/bmj.312.7041.1254

4. Schuit SC, van der Klift M, Weel AE, de Laet CE, Burger H, Seeman E, Hofman A, Uitterlinden AG, van Leeuwen JP, Pols HA (2004) Fracture incidence and association with bone mineral density in elderly men and women: the Rotterdam study. Bone 34:195-202. https://doi.org/10.1016/j.bone.2003.10.001

5. Compston JE, McClung MR, Leslie WD (2019) Osteoporosis. Lancet 393:364-376. https://doi.org/10.1016/s0140-6736(18)32112-3 
6. Zou D, Jiang S, Zhou S, Sun Z, Zhong W, Du G, Li W (2020) Prevalence of osteoporosis in patients undergoing lumbar fusion for lumbar degenerative diseases: a combination of DXA and hounsfield units. Spine (Phila Pa 1976) 45:E406-E410. https://doi.org/10.1097/brs.0000000000003284

7. Pickhardt PJ, Lee LJ, del Rio AM, Lauder T, Bruce RJ, Summers RM, Pooler BD, Binkley N (2011) Simultaneous screening for osteoporosis at CT colonography: bone mineral density assessment using MDCT attenuation techniques compared with the DXA reference standard. J Bone Miner Res 26:2194-2203. https://doi.org/10.1002/jbmr.428

8. Pickhardt PJ, Pooler BD, Lauder T, del Rio AM, Bruce RJ, Binkley N (2013) Opportunistic screening for osteoporosis using abdominal computed tomography scans obtained for other indications. Ann Intern Med 158:588-595. https://doi.org/10.7326/0003-4819-158-8-201304160-00003

9. Zou D, Ye K, Tian Y, Li W, Zhou F, Zhang Z, Lu Z, Xu Z (2020) Characteristics of vertebral CT Hounsfield units in elderly patients with acute vertebral fragility fractures. Eur Spine J 29:10921097. https://doi.org/10.1007/s00586-020-06363-1

10. Lee SJ, Binkley N, Lubner MG, Bruce RJ, Ziemlewicz TJ, Pickhardt PJ (2016) Opportunistic screening for osteoporosis using the sagittal reconstruction from routine abdominal CT for combined assessment of vertebral fractures and density. Osteoporos Int 27:1131-1136. https://doi.org/10.1007/s00198-015-3318-4

11. Lee SJ, Graffy PM, Zea RD, Ziemlewicz TJ, Pickhardt PJ (2018) Future osteoporotic fracture risk related to lumbar vertebral trabecular attenuation measured at routine body CT. J Bone Miner Res 33:860-867. https://doi.org/10.1002/jbmr.3383

12. Schreiber JJ, Anderson PA, Rosas HG, Buchholz AL, Au AG (2011) Hounsfield units for assessing bone mineral density and strength: a tool for osteoporosis management. J Bone Joint Surg Am 93:1057-1063. https://doi.org/10.2106/jbjs.J.00160

13. Pompe E, de Jong PA, de Jong WU, Takx RA, Eikendal AL, Willemink MJ, Oudkerk M, Budde RP, Lammers JW, Hoesein FAM (2016) Inter-observer and inter-examination variability of manual vertebral bone attenuation measurements on computed tomography. Eur Radiol 26:3046-3053. https://doi.org/10.1007/s00330-015-4145-x

14. Zou D, Li W, Xu F, Du G (2019) Use of Hounsfield units of S1 body to diagnose osteoporosis in patients with lumbar degenerative diseases. Neurosurg Focus 46:E6. https://doi.org/10.3171/2019.2.Focus18614

15. Genant HK, Wu CY, van Kuijk C, Nevitt MC (1993) Vertebral fracture assessment using a semiquantitative technique. J Bone Miner Res 8:1137-1148. https://doi.org/10.1002/jbmr.5650080915

16. Prost S, Pesenti S, Fuentes S, Tropiano P, Blondel B (2021) Treatment of osteoporotic vertebral fractures. Orthop Traumatol Surg Res 107:102779. https://doi.org/10.1016/j.otsr.2020.102779

17. Gittoes N (2003) Osteoporosis: pathophysiology and clinical management. Clin Endocrinol (Oxf) 59:826-827. https://doi.org/10.1046/j.1365-2265.2003.01904.x 
18. Eswaran SK, Gupta A, Adams MF, Keaveny TM (2006) Cortical and trabecular load sharing in the human vertebral body. J Bone Miner Res 21:307-314. https://doi.org/10.1359/jbmr.2006.21.2.307

19. Buckens CF, Dijkhuis G, de Keizer B, Verhaar HJ, de Jong PA (2015) Opportunistic screening for osteoporosis on routine computed tomography? An external validation study. Eur Radiol 25:20742079. https://doi.org/10.1007/s00330-014-3584-0

20. Emohare O, Cagan A, Morgan R, Davis R, Asis M, Switzer J, Polly DW, Jr. (2014) The use of computed tomography attenuation to evaluate osteoporosis following acute fractures of the thoracic and lumbar vertebra. Geriatr Orthop Surg Rehabil 5:50-55. https://doi.org/10.1177/2151458514525042

21. Pickhardt PJ, Lauder T, Pooler BD, Del Rio AM, Rosas H, Bruce RJ, Binkley N (2016) Effect of IV contrast on lumbar trabecular attenuation at routine abdominal CT: correlation with DXA and implications for opportunistic osteoporosis screening. Osteoporos Int 27:147-152. https://doi.org/10.1007/s00198-015-3224-9

22. Graffy PM, Lee SJ, Ziemlewicz TJ, Pickhardt PJ (2017) Prevalence of vertebral compression fractures on routine $\mathrm{CT}$ scans according to $\mathrm{L} 1$ trabecular attenuation: determining relevant thresholds for opportunistic osteoporosis screening. AJR Am J Roentgenol 209:491-496. https://doi.org/10.2214/ajr.17.17853

23. Huang CWC, Tseng IJ, Yang SW, Lin YK, Chan WP (2019) Lumbar muscle volume in postmenopausal women with osteoporotic compression fractures: quantitative measurement using MRI. Eur Radiol 29:4999-5006. https://doi.org/10.1007/s00330-019-06034-w

\section{Figures}



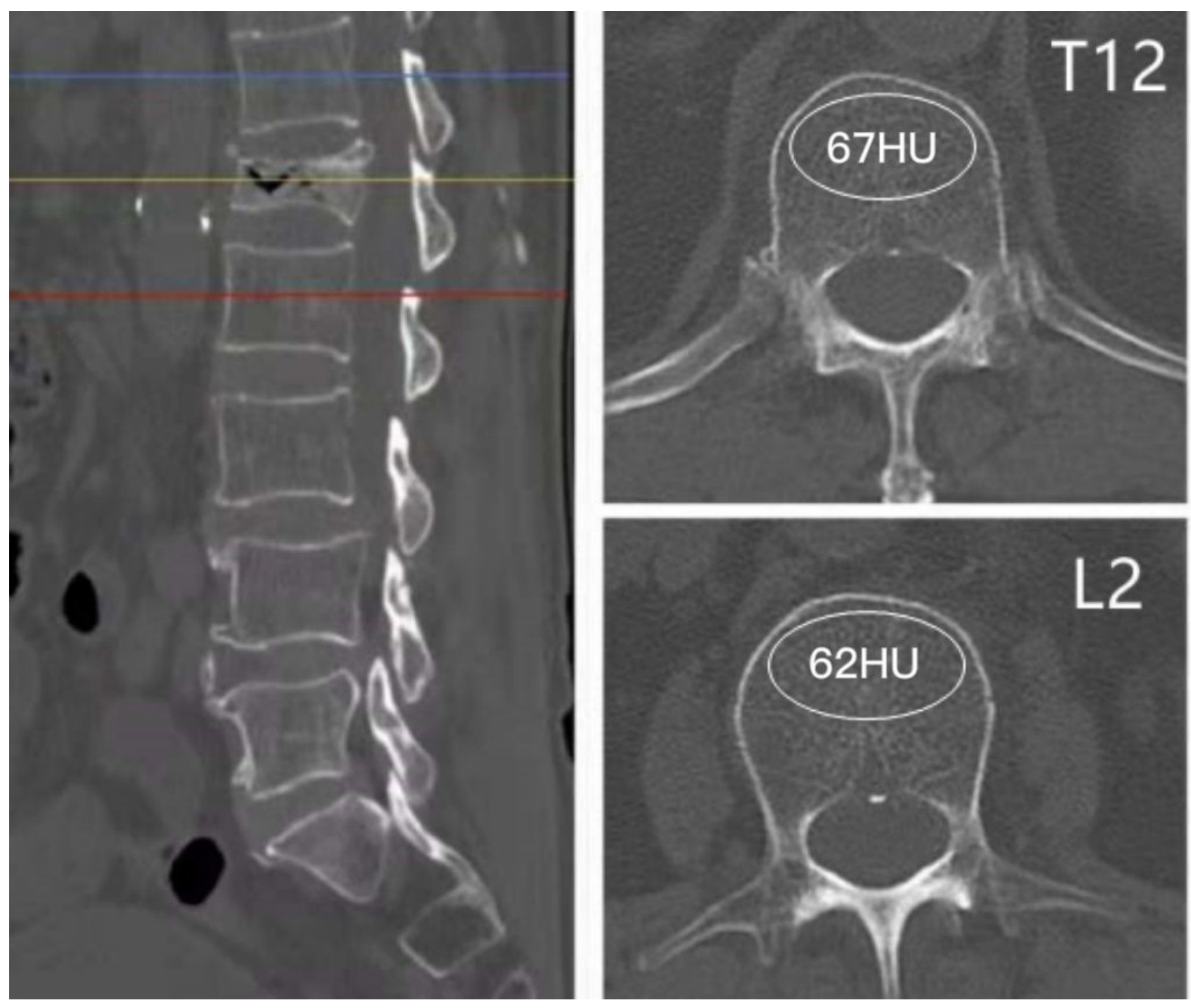

\section{Figure 1}

The patient was an 81-year-old male with a compression fracture of the L1 vertebral body, and the average cancellous bone CT values were used instead by the T12 and L2 vertebral bodies ,because of severe compression. 


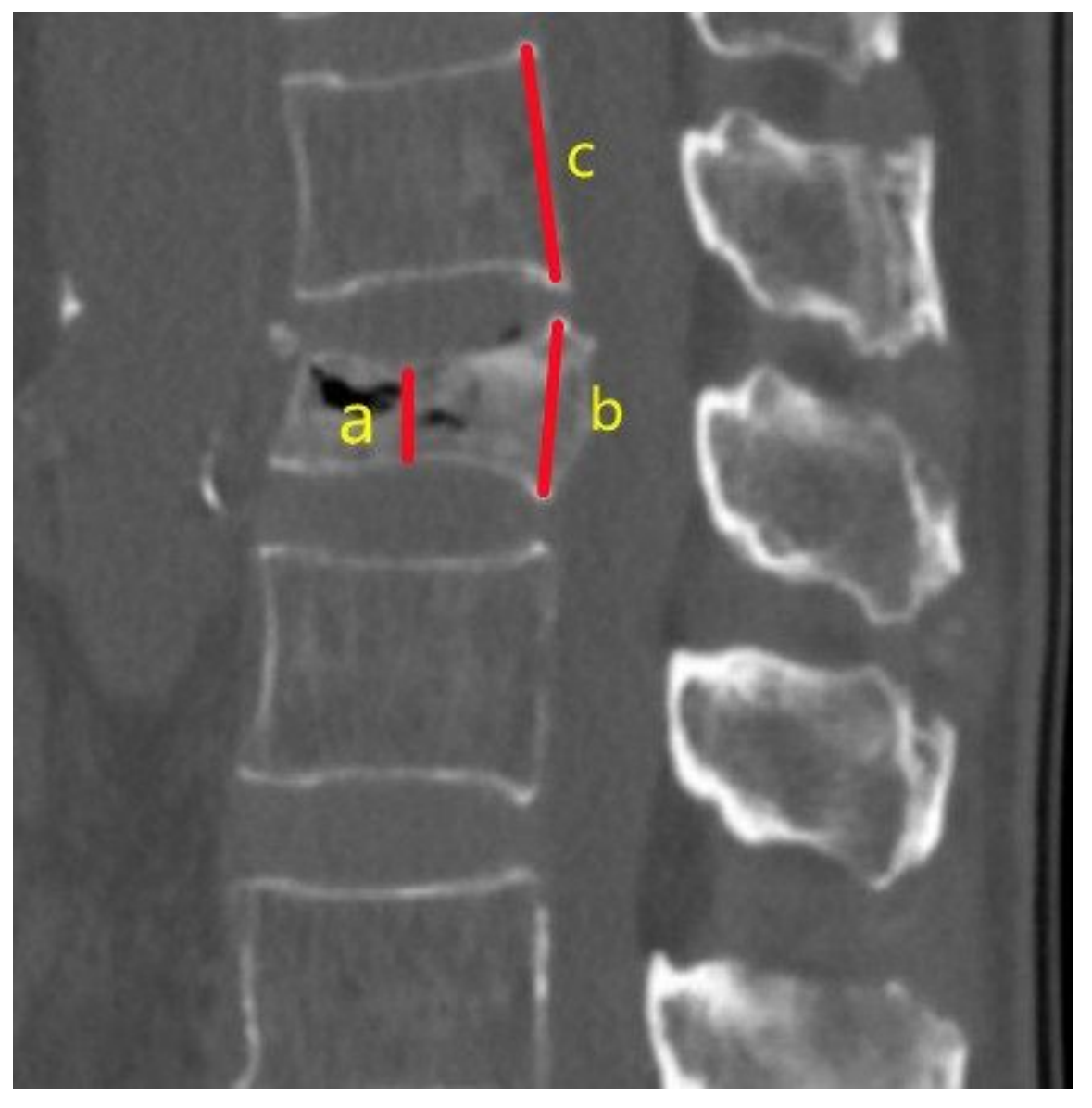

\section{Figure 2}

If the compressed vertebral body had moderate to severe fractures,the degree of vertebral compression ratio for $a / c$, rather than $a / b$. 


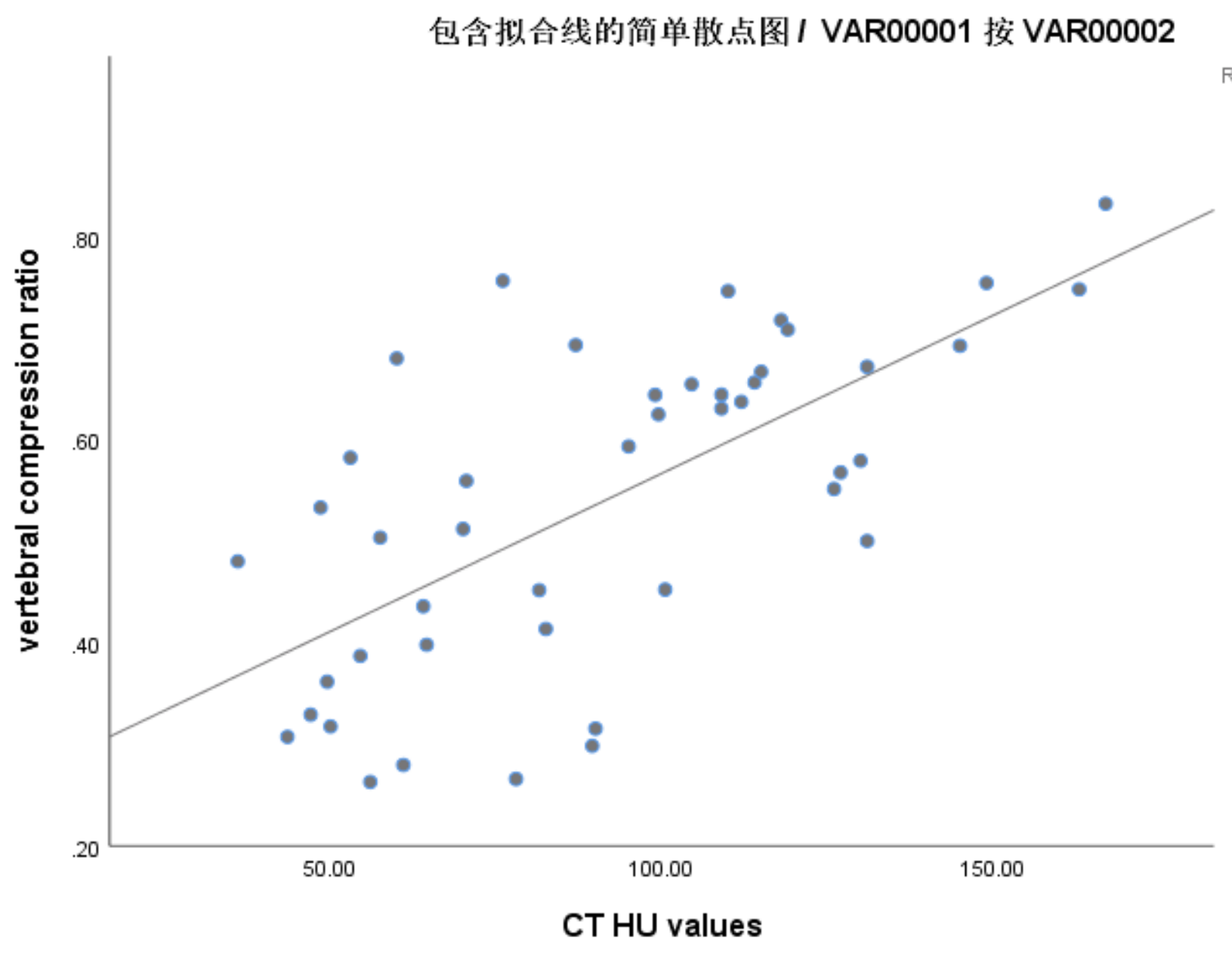

Figure 3

The degree of vertebral compression in thoracolumbar osteoporotic fracture was highly positively correlated with the CT value of cancellous bone $\left(R^{2}\right.$ liner $\left.=0.448\right)$ 